

AKADÉMIAI KIADÓ

Acta Chromatographica

34 (2022) 2, 162-169

DOI:

10.1556/1326.2021.00886

(c) 2021 The Author(s)

ORIGINAL RESEARCH

PAPER

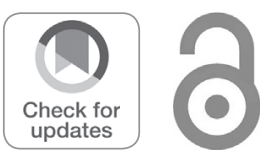

\section{A quantitative HPLC method for simultaneous determination of prodrug of voriconazole and voriconazole in beagle plasma, and its application to a toxicokinetic study}

\author{
YUFA WEN ${ }^{1}$, SHUANG CHEN $^{1}$, YANJUAN YUAN ${ }^{1}$, \\ QING SHAO $^{2}$, XUEJUN HE ${ }^{1}$ and HONGQUN QIAO ${ }^{1 *} \odot$ \\ ${ }^{1}$ Nanjing Tech University, Nanjing 211816, China \\ 2 Jiangsu Provincial Institute of Materia Medica, Nanjing 211816, China
}

Received: December 22, 2020 • Accepted: March 18, 2021

Published online: April 15, 2021

\begin{abstract}
A simple, rapid, efficient and reproducible method based on High Performance Liquid Chromatography (HPLC) for simultaneous determination of prodrug of voriconazole (POV) and voriconazole in beagle plasma has been established and validated. Omeprazole was utilized as the sole internal standard. Analytes and internal standards were extracted through protein precipitation and separated on a Venusil XBP C18 chromatography column $(4.6 \times 250 \mathrm{~mm}, 5 \mu \mathrm{m})$. The mobile phase was methanol and 20 $\mathrm{mmol} / \mathrm{L}$ potassium dihydrogen phosphate. Chromatographic separation was achieved by using an isocratic elution procedure that used $65 \%$ methanol and a flow rate of $1 \mathrm{~mL} / \mathrm{min}$. The ultraviolet (UV) detection wavelength was $256 \mathrm{~nm}$ and the total running time was $15 \mathrm{~min}$. This method showed good linear ranges of 100-75,000 ng/mL for voriconazole prodrug and $200-100,000 \mathrm{ng} / \mathrm{mL}$ for voriconazole respectively. The precision and accuracy were acceptable. Analytes in plasma samples are stable under different temperatures and storage conditions. The developed HPLC method has been successfully applied to the studies of toxicokinetics of POV after intravenous drip in beagle and provided important information for the further development and application.
\end{abstract}

\section{KEYWORDS}

voriconazole prodrug, voriconazole, water solubility, toxicokinetic, beagle, intravenous drip

\section{INTRODUCTION}

Voriconazole (Fig. 1A) is a triazole broad-spectrum antifungal drug that is related to fluconazole structurally, which has been developed as oral and intravenous formulations [1-3]. It is suitable for the treatment of esophageal candidiasis, invasive aspergillosis and other severe fungal infections caused by Fusarium species and Actinomycetes [4]. Based on the structure of fluconazole, a fluorinated pyrimidine was substituted for one of the triazole rings and an $\alpha$-methyl was added to obtain voriconazole, resulting in expanded activity [5]. Its main mechanism is inhibition of cytochrome P450 (CYP 450)-dependent 14 $\alpha$-lanosterol demethylation, which is similar to other triazole antifungal agents [6]. Voriconazole is the drug of choice for treating invasive aspergillosis [7].

Voriconazole has poor aqueous solubility, making it difficult to dose intravenous voriconazole [8]. Derivative of cyclodextrin were usually used to allow for an intravenous administration. Sulfobutylether- $\beta$-cyclodextrin sodium salt (SBECD), a polysubstituted derivative of cyclodextrin, as a excipient of voriconazole for solubilization, was incorporated into parenteral formulation [9]. However, studies have shown that sulfobutyl $\beta$-cyclodextrin has mild nephrotoxicity and cytotoxicity, and may cause hemolysis $[9,10]$. It was found that the accumulation of SBECD in the plasma of patients with renal insufficiency exceeded the normal level and needed hemodialysis to clear $[9,11]$. CVVH (continuous venovenous hemofiltration) can also effectively
Corresponding author. School of Tech University, Puzhu South Road No. 30, Nanjing 211816, China. E-mail: qiaohongqun@njtech.edu.cn 


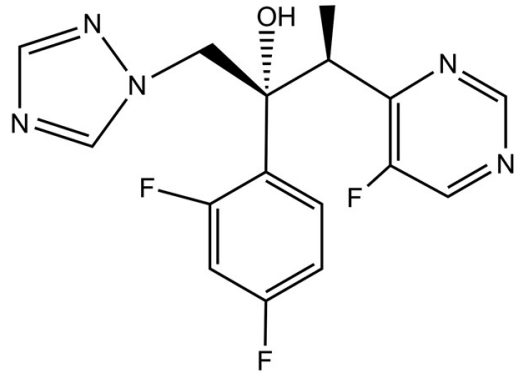

A<smiles>C[C@H](c1ncncc1F)[C@@](Cn1cncn1)(OP(=O)(O)O[Na])c1ccc(F)cc1F</smiles>

B

Fig. 1. The chemical structures of: (A) voriconazole and (B) POV

remove SBECD and reduce the risk of SBECD accumulation [12]. However, these methods are complicated and expensive, so it is essential to find a method to increase the solubility of voriconazole.

Prodrugs, non-pharmacologically active derivatives of the parent drug, have improved delivery characteristics and can release the active drug spontaneously or enzymatically within the body [13]. Phosphate monoesters are easily hydrolyzed by phosphatases. This instability coupled with their high water solubility makes phosphate monoesters an ideal prodrug modification for drugs with low water solubility [14]. Phosphate prodrug modification designs have been successfully applied to many drugs, such as CA1P [15], Fospropofol Disodium [16], Fosphenytoin [17], etc. POV (Fig. 1B) was also the product of this design method. POV was the disodium salt of voriconazole phosphate derivative, which was rapidly metabolized to voriconazole within the body, with better water solubility and lower toxicity $[18,22]$.

By consulting the literature, we have found some High Performance Liquid Chromatography (HPLC) methods for detecting voriconazole in plasma $[19,20]$ while no report based on HPLC method for the determination of voriconazole prodrug (POV) or for the simultaneous detection of POV and voriconazole in plasma are available. Consequently, It makes sense to develop a quantitative method for the simultaneous determination of POV and voriconazole in plasma, so as to provide references for further research of POV.

An efficient and stable HPLC method has been established for simultaneous determination of POV and voriconazole in beagle plasma. This method uses omeprazole as an internal standard (IS) to determine the concentration of two analytes at the same time. The systemic exposure of POV and voriconazole at the design dosages was evaluated by the toxicokinetic research.

\section{EXPERIMENTAL}

\section{Chemical materials}

Voriconazole prodrug for injection was obtained by Shanxi Synthetic Pharmaceutical Co., Ltd., Xian, China. Voriconazole and Omeprazole were obtained from the National Institute for Food and Drug Control, Beijing, China. HPLC grade methanol and HPLC grade acetonitrile were from TEDIA Company Inc., USA. Analytical grade potassium dihydrogen phosphate was supplied by Nanjing Chemical Reagent Co., Ltd., Nanjing, China. HPLC grade water was obtained through a Milli-Q system from Millipore, Bedford, USA.

\section{Equipment and chromatographic conditions}

An Waters 2,695 series HPLC system (Waters, USA) was employed to analysis, which was equipped with a Waters 2,996 PDA detector. Chromatographic separation of all analytes and IS relies on a Venusil XBP C18 chromatography column $(4.6 \times 250 \mathrm{~mm}, 5 \mu \mathrm{m}$; Agela, China $)$ at ambient temperature. The methanol (mobile phase A) and $20 \mathrm{mmol} / \mathrm{L}$ potassium dihydrogen phosphate (mobile phase B) composed mobile phase. Chromatographic separation was performed with isocratic elution, with phase A being $65 \%$ and the flow rate was $1 \mathrm{~mL} / \mathrm{min}$. The injection volume was $10 \mu \mathrm{L}$ and the running time was $15 \mathrm{~min}$. The ultraviolet (UV) detection wavelength was $256 \mathrm{~nm}$. The analysis of Chromatographic Data was completed via Masslynx ${ }^{\circledR}$ Program (Waters, USA).

\section{Preparation of stock solution and standard solution}

Stock solutions of POV and voriconazole (all at 2,000 $\mu \mathrm{g} /$ $\mathrm{mL}$ ) were prepared in methanol separately, and omeprazole $(200 \mu \mathrm{g} / \mathrm{mL})$ was dissolved in acetonitrile. The standard working solutions were obtained by diluting the stock solution with methanol and the concentrations were 2, 5, 20, $50,200,500,1,500 \mu \mathrm{g} / \mathrm{mL}$ for POV and 4, 10, 40, 100, 400, $1,000 \mu \mathrm{g} / \mathrm{mL}$ for voriconazole. Prepared calibration standards by adding $5 \mu \mathrm{L}$ of the corresponding standard working solution to a $90 \mu \mathrm{L}$ beagle blank plasma sample. Than the concentrations of the calibration standard samples we obtained were 100, 250, 1,000, 2,500, 10,000, 25,000 and 75,000 $\mathrm{ng} / \mathrm{mL}$ for POV and 200, 500, 2,000, 5,000, 20,000, 50,000 and $100,000 \mathrm{ng} / \mathrm{mL}$ for voriconazole. Quality control (QC) samples concentrations were set to the following values 
independently: 100 (lower limit of quantification, LLOQ), 250 (LOQ), 2,500 ( $\left.\mathrm{M}_{1} \mathrm{OQ}\right), 25,000\left(\mathrm{M}_{2} \mathrm{OQ}\right), 60,000$ (HOQ) $\mathrm{ng} / \mathrm{mL}$ for POV and $200 \mathrm{LLOQ}, 500$ (LOQ), 5,000 ( $\left.\mathrm{M}_{1} \mathrm{OQ}\right)$, $50,000\left(\mathrm{M}_{2} \mathrm{OQ}\right), 80,000$ (HOQ) $\mathrm{ng} / \mathrm{mL}$ for voriconazole. The IS stock solution was diluted by methanol/water $(50: 50, \mathrm{v} / \mathrm{v})$ to obtain IS working solution $(2,000 \mathrm{ng} / \mathrm{mL})$. All solutions were placed in a $4{ }^{\circ} \mathrm{C}$ environment and equilibrated to room temperature when used.

\section{Plasma pre-treatment}

In a $2 \mathrm{~mL}$ Eppendorf tube, $10 \mu \mathrm{L}$ IS $(2,000 \mathrm{ng} / \mathrm{mL})$ working solution was added into $100 \mu \mathrm{L}$ plasma sample when the plasma sample were thawed to ambient temperature and than vortexed for $30 \mathrm{~s}$. The prepared solution was vortexed for 3 min after adding $300 \mu \mathrm{L}$ of methanol and centrifuged for $10 \mathrm{~min}$ at $15,000 \mathrm{~g}$. Transfer $300 \mu \mathrm{L}$ of the supernatant to a new $1.5 \mathrm{~mL}$ Eppendorf tube and evaporate $2 \mathrm{~h}$ to dryness under vacuum. $100 \mu \mathrm{L}$ of mobile phase was prepared to reconstitute the residue and vortexed to uniformity. Finally, the $10 \mu \mathrm{L}$ sample was analyzed by HPLC system.

\section{Method validation}

According to the Guidance for Industry: Bioanalytical Method Validation issued by the FDA, a series of features of the method were evaluated and validated before the method was put into use [21].

Selectivity. Six independent beagle blank plasma samples were detected for chromatographic interference to evaluate the selectivity. The chromatogram of the blank sample was compared to the liquid chromatographic peak region (POV, voriconazole and IS) of the corresponding spiked plasma sample to observe the presence of endogenous substances.

Linearity and $L L O Q$. The evaluation of linearity required analysis of seven concentration $(100-75,000 \mathrm{ng} / \mathrm{mL}$ for POV, and $200-100,000 \mathrm{ng} / \mathrm{mL}$ for voriconazole) calibration standards on three separate days in a row. The fitting of the calibration curve was completed by a weighted $\left(1 / \mathrm{x}^{2}\right)$ least squares linear regression method (the peak area ratio of the analyte to the IS versus analyte concentration). The accuracy should be within $\pm 20 \%$ and standard deviation should be within $20 \%$ for LLOQ.

Precision and accuracy. Five concentrations of $\mathrm{QC}$ samples (LLOQ, LOQ, $\mathrm{M}_{1} \mathrm{OQ}, \mathrm{M}_{2} \mathrm{OQ}$ and $\mathrm{HOQ}$ ) were analyzed five times within one day to evaluate the intra-day precision and accuracy. The inter-day accuracy and precision were evaluated by analyzing the same four levels of QC samples in 5 batches on three different days. The accuracy of the intraday and inter-day should be within $\pm 15 \%$ (relative error, $\mathrm{RE}$ ) as an acceptable deviation and the precision should not exceed $20 \%$ (relative standard deviation, RSD), while the criterion for LLOQ was within $\pm 20 \%$ for accuracy and not to exceed $20 \%$ for precision.

Extraction recovery. Six replicates analyses were performed at $\mathrm{LOQ}, \mathrm{M}_{1} \mathrm{OQ}$, and $\mathrm{HOQ}$ concentrations to evaluated the analyte recovery and the IS content was measured at 2,000 $\mathrm{ng} / \mathrm{mL}$. Comparing the peak area of the extracted plasma standard with the peak area of the extracted blank plasma spiked at the corresponding concentration, the analyte and IS extraction recovery can be obtained.

Stability. We evaluated the stability of POV in Beagle plasma by six repeated measurements at three different levels of $Q C$ samples (LOQ, $M_{1} O Q, H O Q$ ) in a series of conditions: placing the sample at room temperature for $12 \mathrm{~h}$ and in an autosampler at $4{ }^{\circ} \mathrm{C}$ for $24 \mathrm{~h}$, storage at $-20^{\circ} \mathrm{C}$ for 21 days, and after three freeze-thaw cycles.

Dilution integrity and carryover. In order to prove the reliability of the dilution, we have prepared drug-containing plasma with a concentration above the upper limit of quantification for dilution (dilution from 10,000 to $5,000 \mathrm{ng} / \mathrm{mL}$ and 250,000 to $5,000 \mathrm{ng} / \mathrm{mL}$ for voriconazole, from 5,000 to $2,500 \mathrm{ng} / \mathrm{mL}$ and 125,000 to $\mathrm{ng} / \mathrm{mL}$ for POV). The criterion for accuracy and precision was within $\pm 15 \%$. The response of any peak must be $<20 \%$ of the response of the LLOQ sample.

\section{Toxicokinetic study}

Fourty beagle (8.4-11.6 kg, male, 20; female, 20, Nanjing Yadong Laboratory Animal Research Center Co., Ltd., Nanjing, China) were used for the concomitant toxicokinetic study. The experimental protocol has been approved by the ethical review of the Animal Management and Use Committee of Jiangsu Drug Safety Evaluation Center before implementation and the experiment was conducted according to relevant guidelines and laws and regulations.

All experimental animals were randomly divided into four groups (group A, B, C and D, for each group: male, 5; female, 5). Table 1 shows the experimental groups and dosage regimen. The animals were fasted overnight before the experiment and had free access to water before blood collection. Blood samples $(1.0 \sim 1.5 \mathrm{~mL})$ were collected at specified time ( $0 \mathrm{~h}$ pre-dose and $0.083,1,2,4,7,10$ and $24 \mathrm{~h}$ post-dose on day 1 and day 28) in the experimental protocol by puncturing the subcutaneous venous blood vessel of the forelimb of the beagle into a heparin-treated polythene tubes. The collected plasma samples were immediately centrifuged at 3,000 g for $10 \mathrm{~min}$ at $4{ }^{\circ} \mathrm{C}$ and then stored at

Table 1. The dosage regimen and experimental groups ${ }^{\mathrm{a}}$

\begin{tabular}{lccc}
\hline & & \multicolumn{2}{c}{ Number of animals } \\
\cline { 3 - 4 } Groups & Dosage $(\mathrm{mg} / \mathrm{kg} / \mathrm{day})$ & Male & Female \\
\hline $\mathrm{A}$ & 0 & 5 & 5 \\
$\mathrm{~B}$ & 12.5 & 5 & 5 \\
$\mathrm{C}$ & 25.0 & 5 & 5 \\
$\mathrm{D}$ & 50.0 & 5 & 5 \\
\hline
\end{tabular}

For all groups, animals of group B, C and D were administered Voriconazole prodrug and group A was administered 5\% dextrose injection. All animals were administered by intervenous drip infusion via beagle forefoot vein for consecutive 28 days. 

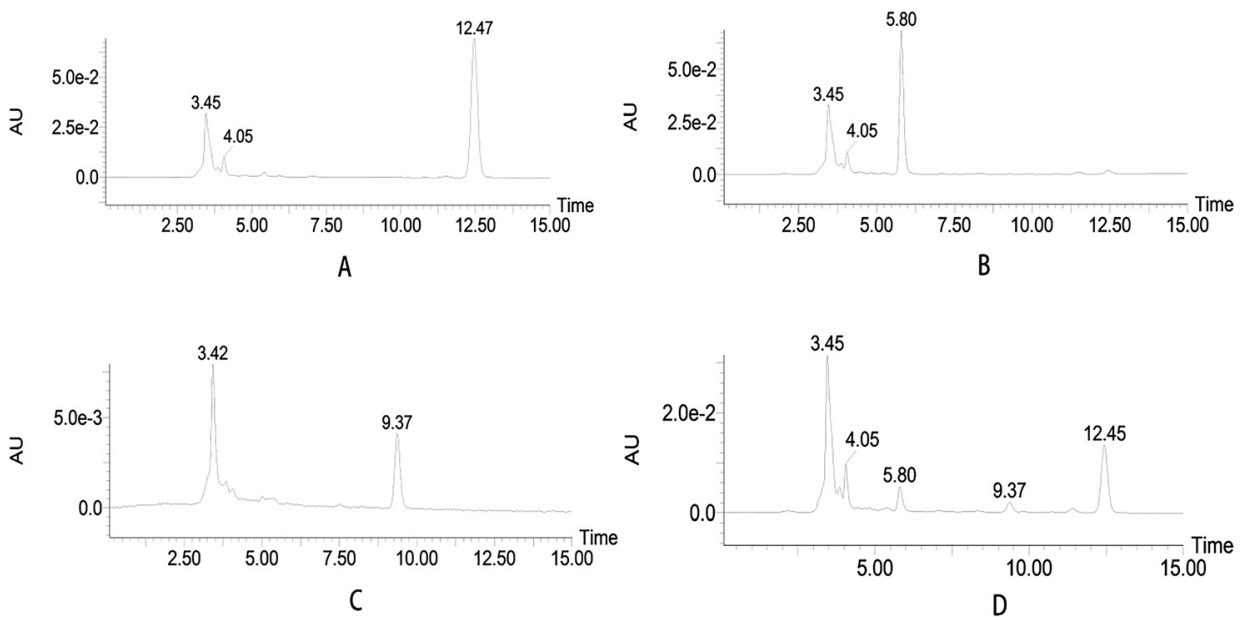

Fig. 2. Representative liquid chromatograms of (A) blank plasma spiked with standard solution of voriconazole, (B) blank plasma spiked with POV standard solution, (C) blank plasma spiked with IS standard solution and (D) the test animal plasma samples

$-20{ }^{\circ} \mathrm{C}$ until preparation. The toxicokinetic parameters of each beagle were calculated by DAS (Drug and Statistical software, version 2.1, Chinese Mathematical Pharmacology Professional Committee, Shanghai, China). Statistical analysis was performed using SPSS 19.0 software, and statistically significant differences were analyzed using an independent-Samples $\mathrm{T}$ Test if it exists. $P<0.05$ means significant difference in the statistical analysis.

\section{RESULTS AND DISCUSSION}

\section{Method optimization}

Biological sample analysis usually uses liquid mass spectrometry technology, with high sensitivity, low sample consumption and fast analysis speed. The water phase of flow phase in this study is a potassium phosphate potassium phosphate solution, which belongs to a non-volatile salt solution, while in theory, LC-MS prohibits the use of any non-volatile salt, will be deposited in the various components of ion transmission, affecting performance and even causing damage. Therefore, this study uses high performance liquid chromatography.

The important influencing factor is the composition of the mobile phase on the experimental result. The most suitablle flow rate was determined to be $1.0 \mathrm{~mL} / \mathrm{min}$ after we investigated a certain range of the flow rate of the mobile phase. Many mobile phases with water/organic solvent compositions and different $\mathrm{pH}$ modifiers has been tried, such as different buffer salt in water or acetonitrile or methanol in various proportions. As a result, an isocratic mobile phase composed of $20 \mathrm{mmol} / \mathrm{L}$ potassium dihydrogen phosphate in water and methanol achieved good chromatographic behaviors. The chromatographic conditions in this study are in compliance with the requirements of the Chinese Pharmacopoeia 2015, the number of theoretical plates is greater than 2,000 , the resolution is greater than 1.5 , the tailing factor is between 0.95 and 1.05 , and the RSD of the repeatability investigation is less than $2.0 \%$.

There are many techniques for sample pretreatment. Commonly used are protein precipitation (PPT), solid phase extraction (SPE), and liquid-liquid extraction (LLE). PPT was chosen as the sample preparation method for this experiment because of its simple operation and higher recovery. Methanol was chosen as the precipitant in this experiment, because in various precipitants, such as acetonitrile, acetonitrile/water, methanol and methanol/water, methanol showed better recovery rate.

\section{Method validation}

Selectivity. The representative chromatograms of blank beagle plasma, blank beagle plasma added with voriconazole, blank beagle plasma added with POV, blank beagle plasma added with IS and blank beagle plasma sample added with voriconazole,POV, and IS simultaneously were shown in Fig. 2. The retention times were 12.47, 5.80 and $9.37 \mathrm{~min}$ for the voriconazole, POV and IS, respectively. Voriconazole, POV and internal standard Omeprazole achieved baseline separation with good peak shape and no peak interference measurement. The method has high specificity and can accurately determine the concentration of voriconazole and POV in plasma with high sensitivity.

Linearity and LLOQ. The correlation curves in Fig. 3 shows a good linear relationship when the concentration range was $200-100,000 \mathrm{ng} / \mathrm{mL}$ for voriconazole and $100-75,000 \mathrm{ng} / \mathrm{mL}$ for POV. The correlation coefficients ( $r$ ) were 0.9999 for voriconazole and 0.9995 for POV. Table 2 shows the precision and accuracy of the LLOQ. The LLOQ of voriconazole was $200 \mathrm{ng} / \mathrm{mL}$, and the POV was $100 \mathrm{ng} / \mathrm{mL}$.

Accuracy and precision. Table 2 shows the accuracy and precision data of voriconazole and POV. The data clearly 


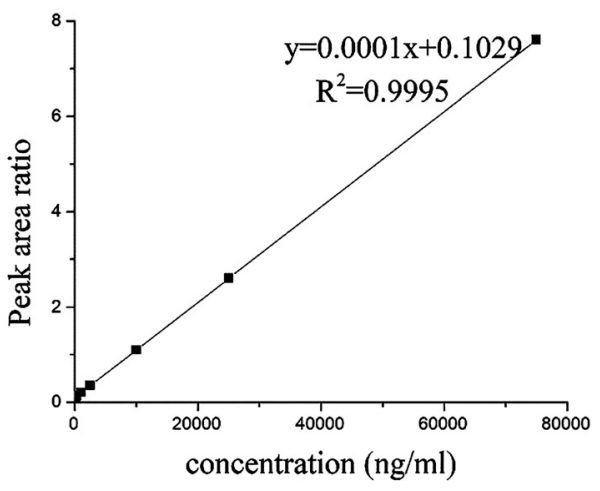

A

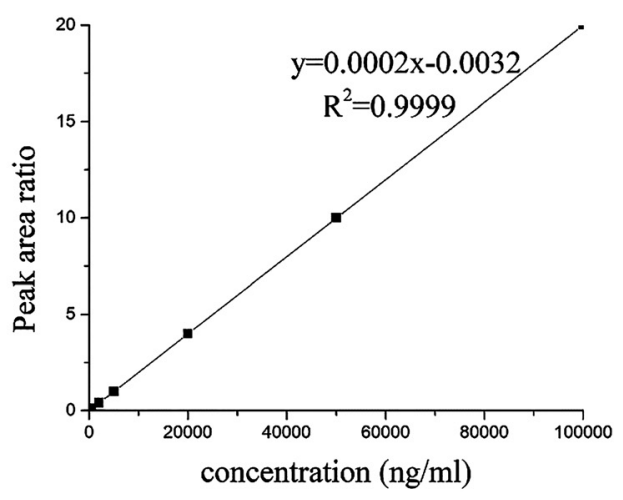

B

Fig. 3. Correlation curves of (A) POV and (B) voriconazole

Table 2. Intra-day and inter-day accuracies and precisions of Voriconazole and POV $(n=5)$

\begin{tabular}{|c|c|c|c|c|c|c|c|}
\hline \multirow[b]{2}{*}{ Analytes } & \multirow[b]{2}{*}{$\begin{array}{c}\text { Nominal } \\
\text { concentration } \\
(\mathrm{ng} / \mathrm{mL})\end{array}$} & \multicolumn{3}{|c|}{ Intra-day } & \multicolumn{3}{|c|}{ Inter-day } \\
\hline & & $\begin{array}{c}\text { Measured } \\
\text { concentration } \\
(\mathrm{ng} / \mathrm{mL})\end{array}$ & $\begin{array}{l}\text { Precision } \\
\text { RSD (\%) }\end{array}$ & $\begin{array}{c}\text { Accuracy } \\
\text { RE (\%) }\end{array}$ & $\begin{array}{c}\text { Measured } \\
\text { concentration } \\
(\mathrm{ng} / \mathrm{mL})\end{array}$ & $\begin{array}{l}\text { Precision } \\
\text { RSD (\%) }\end{array}$ & $\begin{array}{c}\text { Accuracy } \\
\text { RE (\%) }\end{array}$ \\
\hline \multirow[t]{5}{*}{ Voriconazole } & 200 & 206.53 & 2.56 & 3.27 & 208.45 & 3.56 & 4.23 \\
\hline & 500 & 508.66 & 2.04 & 1.73 & 526.11 & 3.13 & 5.22 \\
\hline & 5,000 & $5,319.08$ & 1.11 & 6.38 & $5,446.74$ & 2.34 & 8.93 \\
\hline & 50,000 & $54,304.14$ & 1.62 & 8.60 & $54,278.97$ & 1.88 & 8.56 \\
\hline & 80,000 & $85,325.10$ & 2.30 & 6.66 & $84,876.49$ & 4.25 & 6.09 \\
\hline \multirow[t]{5}{*}{ POV } & 100 & 102.90 & 1.54 & 2.90 & 106.16 & 5.45 & 6.16 \\
\hline & 250 & 242.18 & 3.20 & -3.13 & 245.00 & 3.34 & -2.00 \\
\hline & 2,500 & $2,479.74$ & 1.66 & -0.81 & $2,511.88$ & 5.06 & 0.48 \\
\hline & 25,000 & $24,311.62$ & 0.35 & -2.75 & $24,207.57$ & 2.12 & -3.17 \\
\hline & 60,000 & $58,413.44$ & 2.65 & -2.64 & $57,246.13$ & 2.83 & -4.59 \\
\hline
\end{tabular}

indicated that the method has good reproducibility and reliability for the concentration analysis of voriconazole and POV in beagles plasma samples simultaneously.The relative errors of accuracy (RE, \%) of voriconazole plasma samples were between 1.73 and $8.93 \%$, while the precision (RSD, \%) were within $4.25 \%$. The RE of POV were between -4.59 and $6.16 \%$, and the RSD were within $5.45 \%$.

Extraction recovery. The recovery of voriconazole, POV and IS are presented in Table 3. The results indicated that the average recovery of all analytes in this method was $>89.66 \%$. The method has a high recovery rate.

Table 3. The recovery of Voriconazole, POV and IS $(n=5)$

\begin{tabular}{lcrc}
\hline & & \multicolumn{2}{c}{ Recovery (\%) } \\
\cline { 3 - 4 } Analytes & $\begin{array}{c}\text { Nominal concentration } \\
\text { (ng/mL) }\end{array}$ & Mean \pm SD & $\begin{array}{c}\text { RSD } \\
(\%)\end{array}$ \\
\hline Voriconazole & 500 & $96.88 \pm 2.15$ & 2.22 \\
& 5,000 & $91.14 \pm 3.82$ & 4.19 \\
POV & 80,000 & $94.41 \pm 4.99$ & 5.28 \\
& 250 & $103.21 \pm 3.62$ & 3.51 \\
& 2,500 & $89.66 \pm 3.99$ & 4.45 \\
IS & 60,000 & $97.58 \pm 1.78$ & 1.82 \\
& 2,000 & $96.02 \pm 6.34$ & 6.61 \\
\hline
\end{tabular}

Stability. The stability results of voriconazole and POV are listed in Table 4. Based on the results we can draw a conclusion that voriconazole and POV in plasma were stable after placing the sample at room temperature for $12 \mathrm{~h}$ and in an autosampler at $4{ }^{\circ} \mathrm{C}$ for $24 \mathrm{~h}$, storage at $-20{ }^{\circ} \mathrm{C}$ for 21 days, and after three freeze-thaw cycles.

Dilution integrity and carryover. By diluting with beagle plasma, the upper concentration limits can be extended to 50 -fold. The accuracy was less than $9.96 \%$ for dilution integrity samples and the precision was within $2.28 \%$. No carryover effect of any analyte were observed during the experiment.

\section{Toxicokinetic study}

Until now, there have been no reports on the toxicokinetics of POV in beagle dog. The HPLC method established and validated in this study has been successfully applied to a toxicokinetic study of the four-week toxicity of POV in beagles. The mean $( \pm \mathrm{SD})$ plasma concentration-time profiles of POV and its metabolite voriconazole on day 1 and day 28 after daily i.v.gtt administration of 12.5, 25.0 and 50.0 $\mathrm{mg} / \mathrm{kg} /$ day of POV to beagles for 28 days are listed in Fig. 4. Table 5 summarized the toxicokinetic parameters. 
Table 4. Stability data of Voriconazole and POV in beagles plasma under different condition $(n=5)$

\begin{tabular}{|c|c|c|c|c|c|c|c|c|c|}
\hline \multirow[b]{2}{*}{ Analytes } & \multirow{2}{*}{$\begin{array}{c}\text { Nominal } \\
\text { concentration }(\mathrm{ng} / \mathrm{mL})\end{array}$} & \multicolumn{2}{|c|}{$\begin{array}{c}\text { Room temperature, } \\
12 \mathrm{~h} \\
\end{array}$} & \multicolumn{2}{|c|}{$\begin{array}{c}\text { Autosampler, } 20^{\circ} \mathrm{C}, \\
24 \mathrm{~h}\end{array}$} & \multicolumn{2}{|c|}{$\begin{array}{l}\text { Three freeze-thaw } \\
\text { cycles }\end{array}$} & \multicolumn{2}{|c|}{$-20{ }^{\circ} \mathrm{C}, 21$ days } \\
\hline & & $\mathrm{RE}(\%)$ & RSD (\%) & $\mathrm{RE}(\%)$ & RSD (\%) & $\mathrm{RE}(\%)$ & RSD (\%) & $\mathrm{RE}(\%)$ & RSD (\%) \\
\hline \multirow[t]{3}{*}{ Voriconazole } & 500 & 4.29 & 0.59 & 5.03 & 0.44 & 8.20 & 1.82 & 8.48 & 1.25 \\
\hline & 5,000 & 6.34 & 1.35 & 5.10 & 0.73 & 5.67 & 1.27 & 8.46 & 0.76 \\
\hline & 80,000 & 6.23 & 1.46 & 6.26 & 1.12 & 6.07 & 1.73 & 6.31 & 2.07 \\
\hline \multirow[t]{3}{*}{ POV } & 250 & -4.16 & 2.77 & 0.42 & 3.35 & -1.90 & 3.53 & -0.17 & 2.39 \\
\hline & 2,500 & 0.42 & 0.83 & 0.71 & 2.09 & -1.36 & 1.77 & 2.35 & 1.51 \\
\hline & 60,000 & -3.81 & 0.39 & -5.49 & 2.70 & -5.48 & 0.84 & -5.08 & 1.98 \\
\hline
\end{tabular}
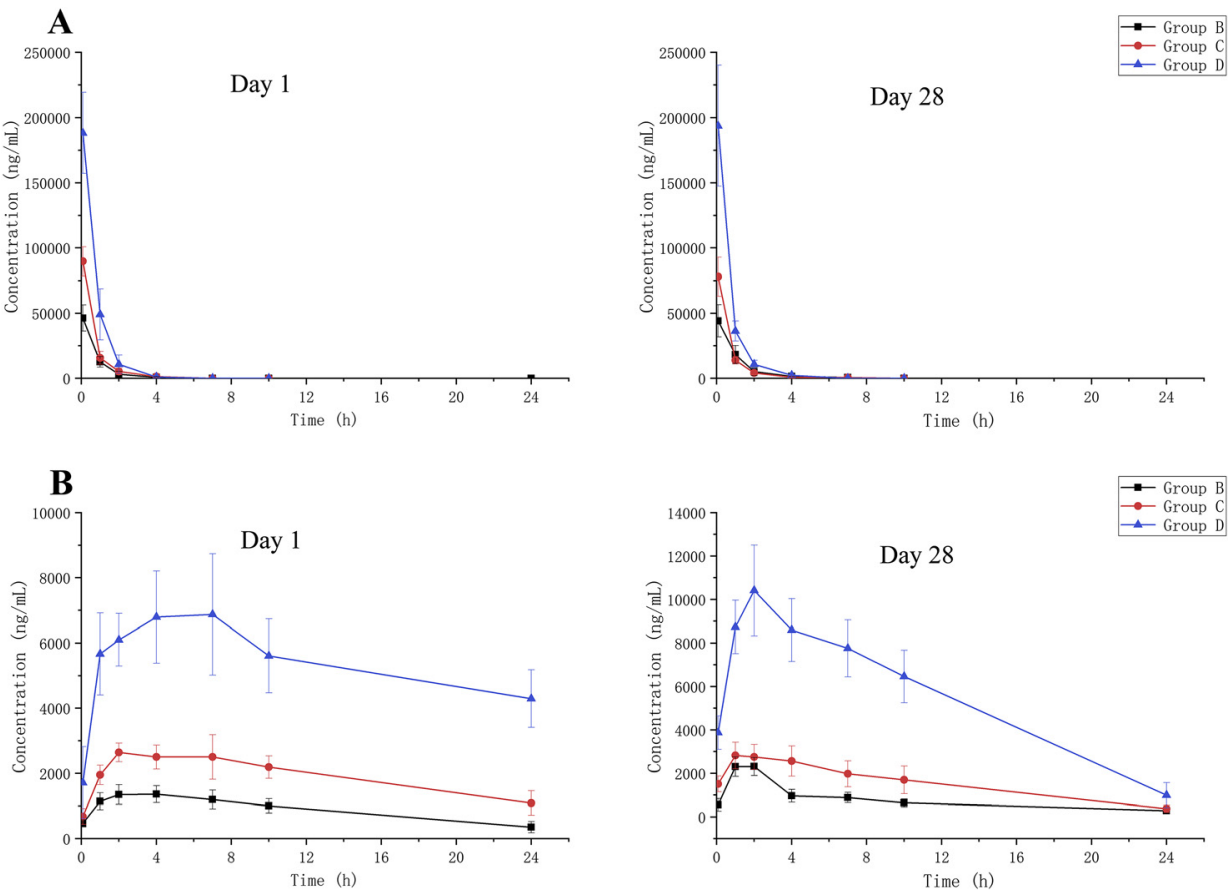

Fig. 4. Mean plasma concentration-time profiles of (A) POV and (B) voriconazole after i.v.gtt administration of $12.5,25 \mathrm{and} 50 \mathrm{mg} / \mathrm{kg}$ of POV in beagles on day 1 and day 28

The results showed that the concentration of POV in plasma reached a maximum rapidly after $5 \mathrm{~min}$ of administration and POV will be rapidly converted to voriconazole it was basically consistent with the toxicokinetic study results of POV in rats [22]. After i.v.gtt administration of POV, no significant difference between day 1 and day 28 in terms of plasma concentration-time profiles was observed, while the time for metabolite plasma concentration to reach the maximum was shortened, peak concentration increased and elimination rate was speeding up.

The parameters $\mathrm{AUC}_{(0-\mathrm{t})}$ and $\mathrm{C}_{\max }$ of $\mathrm{POV}$ and its metabolite voriconazole were analyzed by linear regression. The results showed that in the dose range of $12.5 \sim 50 \mathrm{mg} /$ $\mathrm{kg}, \mathrm{AUC}_{(0-\mathrm{t})}$ showed a linear relationship with dose of POV and voriconazole $\left(\mathrm{R}^{2}>0.94\right)$ and $C \max$ showed a linear relationship with dose of POV and voriconazole $\left(R^{2}>0.92\right)$. The results were consistent with the toxicokinetic study results of POV in rats [22]. It is noteworthy that the pharmacokinetics of voriconazole are nonlinear [23].
The level of exposure of prodrug of voriconazole in vivo after multiple administrations was substantially consistent with the level of first administration. The exposure level of its metabolite voriconazole was basically the same in the high-dose group (Group D) compared with the first time, and the medium- and low-dose groups (Group C and B) showed a significant decreasing trend after multiple administrations. The results of independent sample t-test for toxicokinetic parameters $\mathrm{AUC}_{(0-\mathrm{t})}, \mathrm{MRT}_{(0-\mathrm{t})}, \mathrm{T}_{\max }$ and $\mathrm{C}_{\max }$ showed that there were no significant differences in other parameters except for $\mathrm{AUC}_{(0-\mathrm{t})}$ of metabolite voriconazole in high-dose group between males and females. Overall, we suppose that there was no obvious gender differences and accumulations were found of POV in beagle plasma when the dose range is $12.5 \sim 50.0 \mathrm{mg} / \mathrm{kg}$ and the safe dose was $12.5 \mathrm{mg} / \mathrm{kg}$. In the toxicity study of POV in rats, when the dose range was $30 \sim 120 \mathrm{mg} / \mathrm{kg}$, the safe dose was $60 \mathrm{mg} / \mathrm{kg}$, and a gender difference was found [22]. This suggests that there were species differences in POV. 
Table 5. Toxicokinetics parameters of POV and Voriconazole in beagle plasma $(n=5)$

\begin{tabular}{|c|c|c|c|c|}
\hline \multirow[b]{2}{*}{ POV } & \multicolumn{2}{|c|}{ Day 1} & \multicolumn{2}{|c|}{ Day 28} \\
\hline & Male & Female & Male & Female \\
\hline \multicolumn{5}{|c|}{ Group B (12.5 mg/kg/day) } \\
\hline $\operatorname{AUC}_{(0-24 \mathrm{~h})}(\mu \mathrm{g} \mathrm{h} / \mathrm{L})$ & $37,724.3 \pm 11,788.9$ & $48,987.1 \pm 8,460.5$ & $53,192.6 \pm 11,117.3$ & $51,657.8 \pm 19,686.6$ \\
\hline $\mathrm{C}_{\max }(\mu \mathrm{g} / \mathrm{L})$ & $41,215.3 \pm 7,290.3$ & $51,493.0 \pm 10,249.8$ & $46,309.9 \pm 10,372.8$ & $42,092.0 \pm 15,055.1$ \\
\hline $\mathrm{T}_{\max }(\mathrm{h})$ & 0.083 & 0.083 & 0.083 & 0.083 \\
\hline $\mathrm{MRT}_{(0-24 \mathrm{~h})}(\mathrm{h})$ & $0.54 \pm 0.22$ & $0.67 \pm 0.15$ & $0.84 \pm 0.17$ & $0.98 \pm 0.28$ \\
\hline \multicolumn{5}{|c|}{ Group C $(25.0 \mathrm{mg} / \mathrm{kg} /$ day $)$} \\
\hline $\operatorname{AUC}_{(0-24 \mathrm{~h})}(\mu \mathrm{g} \mathrm{h} / \mathrm{L})$ & $67,267.2 \pm 6,212.4$ & $77,556.3 \pm 18,893.5$ & $67,752.8 \pm 14,128.7$ & $59,808.4 \pm 5,774.6$ \\
\hline $\mathrm{C}_{\max }(\mu \mathrm{g} / \mathrm{L})$ & $82,922.6 \pm 6,205.6$ & $96,590.4 \pm 11,199.0$ & $84,384.8 \pm 19,331.2$ & $71,443.0 \pm 4,644.7$ \\
\hline $\mathrm{T}_{\max }(\mathrm{h})$ & 0.083 & 0.083 & 0.083 & 0.083 \\
\hline \multicolumn{4}{|c|}{ Group D (50.0 mg/kg/day) } & $0.62 \pm 0.17$ \\
\hline $\operatorname{AUC}_{(0-24 \mathrm{~h})}(\mu \mathrm{g} \mathrm{h} / \mathrm{L})$ & $141,933.0 \pm 16,281.4$ & $192,166.8 \pm 46,344.3$ & $167,566.3 \pm 10,004.0$ & $154,191.7 \pm 44,610.2$ \\
\hline $\mathrm{C}_{\max }(\mu \mathrm{g} / \mathrm{L})$ & $172,095.7 \pm 21,916.1$ & $204,471.1 \pm 32,242.7$ & $208,671.4 \pm 15,561.1$ & $179,013.4 \pm 63,705.4$ \\
\hline $\mathrm{T}_{\max }(\mathrm{h})$ & 0.083 & 0.083 & 0.083 & 0.083 \\
\hline $\mathrm{MRT}_{(0-24 \mathrm{~h})}(\mathrm{h})$ & $0.45 \pm 0.10$ & $0.57 \pm 0.12$ & $0.58 \pm 0.08$ & $0.60 \pm 0.11$ \\
\hline \multirow[t]{2}{*}{ Voriconazole } & \multicolumn{2}{|c|}{ Day 1} & \multicolumn{2}{|c|}{ Day 28} \\
\hline & Male & Female & Male & Female \\
\hline \multicolumn{5}{|c|}{ Group B (12.5 mg/kg/day) } \\
\hline $\operatorname{AUC}_{(0-24 \mathrm{~h})}(\mu \mathrm{g} \mathrm{h} / \mathrm{L})$ & $22,372.8 \pm 3,713.6$ & $20,286.7 \pm 4,879.7$ & $14,585.7 \pm 5,682.8$ & $11,039.6 \pm 1,631.0$ \\
\hline $\mathrm{C}_{\max }(\mu \mathrm{g} / \mathrm{L})$ & $1,527.6 \pm 297.2$ & $1,319.4 \pm 141.7$ & $2,603.7 \pm 345.5$ & $2,486.3 \pm 352.4$ \\
\hline $\mathrm{T}_{\max }(\mathrm{h})$ & $2.4 \pm 0.9$ & $3.6 \pm 0.9$ & $1.6 \pm 0.5$ & $1.4 \pm 0.5$ \\
\hline $\mathrm{MRT}_{(0-24 \mathrm{~h})}(\mathrm{h})$ & $8.37 \pm 0.63$ & $9.18 \pm 0.97$ & $4.52 \pm 1.50$ & $3.88 \pm 0.22$ \\
\hline \multicolumn{5}{|c|}{ Group C (25.0 mg/kg/day) } \\
\hline $\operatorname{AUC}_{(0-24 \mathrm{~h})}(\mu \mathrm{g} \mathrm{h} / \mathrm{L})$ & $45,663.8 \pm 5,735.0$ & $46,787.0 \pm 10,767.9$ & $39,809.6 \pm 6,795.2$ & $34,150.7 \pm 11,116.1$ \\
\hline $\mathrm{C}_{\max }(\mu \mathrm{g} / \mathrm{L})$ & $2,662.5 \pm 213.3$ & $2,967.1 \pm 707.1$ & $3,201.6 \pm 630.7$ & $2,965.9 \pm 603.7$ \\
\hline $\mathrm{T}_{\max }(\mathrm{h})$ & $3.4 \pm 2.2$ & $3.0 \pm 2.2$ & $1.4 \pm 0.5$ & $2.4 \pm 1.5$ \\
\hline $\mathrm{MRT}_{(0-24 \mathrm{~h})}(\mathrm{h})$ & $10.09 \pm 0.53$ & $9.55 \pm 0.57$ & $7.96 \pm 0.62$ & $7.4 \pm 0.4$ \\
\hline \multicolumn{5}{|c|}{ Group D (50.0 mg/kg/day) } \\
\hline $\operatorname{AUC}_{(0-24 \mathrm{~h})}(\mu \mathrm{g} \mathrm{h} / \mathrm{L})$ & $137,002.7 \pm 12,755.8$ & $124,753.1 \pm 18,942.3$ & $147,376.7 \pm 13,832.4$ & $118,078.3 \pm 11,799.1^{\#}$ \\
\hline $\mathrm{C}_{\max }(\mu \mathrm{g} / \mathrm{L})$ & $7,283.6 \pm 660.2$ & $8,520.6 \pm 1,931.1$ & $11,524.4 \pm 1,538.3$ & $9,676.2 \pm 2,099.2$ \\
\hline $\mathrm{T}_{\max }(\mathrm{h})$ & $3.6 \pm 2.3$ & $5.2 \pm 1.6$ & $2.4 \pm 0.9$ & $1.8 \pm 0.4$ \\
\hline $\mathrm{MRT}_{(0-24 \mathrm{~h})}(\mathrm{h})$ & $11.10 \pm 0.33$ & $10.77 \pm 0.66$ & $7.71 \pm 0.61$ & $7.38 \pm 0.58$ \\
\hline
\end{tabular}

a "Significant difference between males and females, $P<0.05$.

\section{CONCLUSIONS}

This study has established and validated a simple, fast, specific and reproducible HPLC method to determine the concentration of POV and its metabolite voriconazole in beagle plasma simultaneously. This effective method is easy to implement and suitable for the analysis of multiple biological samples. This method has been successfully applied to the pharmacokinetics and toxicokinetics of POV (the results of pharmacokinetics and long-term toxicity will be given in other articles), and will provide a reference and basis for further research of POV. The toxicokinetics results of POV in the beagle indicated that after 28 days of repeated administration of POV, there was no difference in gender and no accumulation of POV and its metabolites. Under the experimental conditions, the safe dose of i.v.gtt administration of POV in beagle was $12.5 \mathrm{mg} / \mathrm{kg}$.
Declaration of interest: The authors do not have any conflicts of interest to declare.

\section{REFERENCES}

1. Jeu, L.; Piacenti, F. J.; Lyakhovetskiy, A. G.; Fung, H. B. Clin. Ther. 2003, 25, 1321-81.

2. Purkins, L.; Wood, N.; Greenhalgh, K.; Allen, M. J.; Oliver, S. D. Br. J. Clin. Pharmacol. 2003, 56, 10-6.

3. Purkins, L.; Wood, N.; Ghahramani, P.; Love, E. R.; Eve, M.; Fielding, A. Br. J. Clin. Pharmacol. 2003, 56, 37-44.

4. Muldrew, K. M.; Maples, H. D.; Stowe, C. D.; Jacobs, R. F. Pharmacotherapy 2005, 25, 893-8.

5. Johnson, L. B.; Kauffman, C. A. Clin. Infect. Dis. 2003, 36, 630-7.

6. Sanati, H.; Belanger, P.; Fratti, B.; Ghannoum, M. Antimicrob. Agents. Ch. 1997, 41, 2492-6. 
7. Park, S. Y.; Yoon, J. A.; Kim, S. H. Korean J. Intern. Med. 2017, 32, 805-12.

8. Füredi, P.; Pápay, Z. E.; Kovács, K.; Kiss, B. D.; Ludányi, K.; Antal, I.; Klebovich, I. J. Pharmaceut. Biomed. 2017, 132, 184-9.

9. Luke, D. R.; Tomaszewski, K.; Damle, B.; Schlamm, H. T. J. Pharm. SCI-US. 2010, 99, 3291-301.

10. Rajewski, R. A.; Traiger, G.; Bresnahan, J.; Jaberaboansari, P.; Stella, V. J.; Thompson, D. O. J. Pharm. Sci. 1995, 84, 927-32.

11. Damle, B. Nephrol. Dial. Transol. 2012, 27, 1207-12.

12. Kiser, T. H.; Fish, D. N.; Aquilante, C. L., et al. Critical. Care. 2015, $19,32$.

13. Freeman, S.; Ross, K. C. J. Med. Chem. 1997, 34, 111-47.

14. Rautio, J.; Kumpulainen, H.; Heimbach, T., et al. Nat. Rev. Drug. Discov. 2008, 7, 255-70.

15. Shirali, A.; Sriram, M.; Hall, J. J.; Nguyen, B. L.; Guddneppanavar, R.; Hadimani, M. B. J. Nat. Prod. 2009, 72, 414-21.
16. Kumpulainen, H.; Järvinen, T.; Mannila, A.; Leppänen, J.; Nevalainen, T.; Mäntylä, A.; Rautio, J. Eur. J. Pharm. Sci. 2008, 34, 110-7.

17. Stella, V. J.; Nti-Addae, K. W. Adv. Drug. Deliver. Rev. 2007, 59, $677-94$.

18. Shaanxi Synthetic Pharmaceutical Co., Ltd. CN Pat., CN 107652325 A, 2018.

19. Srinubabu, G.; Raju, C. A. I.; Sarath, N. Talanta 2007, 71, 1424-9.

20. Chawla, P. K.; Dherai, A. J.; Ashavaid, T. F. Indian J. Biochem. Biophys. 2015, 31, 209-14.

21. Food and Drug Administration, Guidance for Industry: Bioanalytical Method Validation. US, 2013.

22. Juemin, C.; Jing, L.; Bo, Z., et al. Regul. Toxicol. Pharm. 2019, 104, 8-13.

23. Pfifizer. FDA Antiviral Drugs Advisory Committee Briefifing Document for Voriconazole (Oral and Intravenous Formulations); FDA, Rockville, MD, 2001. http://www.fda.gov/ohrms/dockets/AC/ 01/briefifing/3792b2_01_Pfifizer.pdf, Accessed date: 15 January 2008. 